\title{
PROCESSO DE FORMAÇÃO DA(O) ENFERMEIRA(O) NA CONTEMPORANEIDADE: DESAFIOS E PERSPECTIVAS
}

\author{
Mary Gomes Silva ${ }^{1}$, Josicelia Dumêt Fernandes², Giselle Alves da Silva Teixeira², Rosana Maria de \\ Oliveira Silva
}

\footnotetext{
${ }^{1}$ Doutoranda do Programa de Pós-Graduação em Enfermagem da Universidade Federal da Bahia (UFBA). Docente do Curso de Graduação em Enfermagem da Universidade do Estado da Bahia. Bahia, Brasil. E-mail: mago13silva@gmail.com

${ }^{2}$ Doutora em Enfermagem. Professor Titular da Escola de Enfermagem da UFBA. Pesquisadora do CNPq. Bahia, Brasil. E-mail: dumet@ufba.br

${ }^{3}$ Mestranda do Programa de Pós-Graduação em Enfermagem da UFBA. Bolsista da FAPESB. Bahia, Brasil. E-mail: giselletnf@ hotmail.com

${ }^{4}$ Doutoranda do Programa de Pós-Graduação em Enfermagem da UFBA. Docente da Escola de Enfermagem da UFBA. Bahia, Brasil. E-mail: rosanaosilva@ibest.com.br
}

RESUMO: Este artigo objetiva refletir acerca do processo de formação da(o) enfermeira(o) na contemporaneidade. Trata-se de uma reflexão subsidiada por uma pesquisa bibliográfica em artigos publicados nas bases de dados LILACS e SciELO, utilizando os descritores currículo, ensino, educação, enfermagem. Foram encontrados 39 artigos; selecionados 25, através da leitura dos respectivos resumos. Após, utilizou-se o método de leitura científica, organizando o artigo em dois tópicos: desafios na trajetória da educação na enfermagem no Brasil e, desafios e perspectivas na reorientação do processo de formação da(o) enfermeira (o). Reitera-se que a resistência às mudanças, a pouca reflexão sobre a docência, o distanciamento dos serviços de saúde, com o reforço à clássica dicotomia entre o pensar e o fazer, presentes em boa parte da prática dos docentes; constituem alguns dos desafios que necessitam de enfrentamento e superação para melhoria da formação do enfermeiro na contemporaneidade.

DESCRITORES: Currículo. Ensino. Educação. Enfermagem.

\section{CONTEMPORARY FORMAL NURSING EDUCATION PROCESS: CHALLENGES AND PERSPECTIVES}

\begin{abstract}
The objective of this article is to reflect on the contemporary nursing formal education process. It is a consideration subsidized by bibliographical research in articles published in the LILACS and SciIELO data-bases, using the following keywords: curriculum, teaching, education, and nursing. Thirty-nine articles were found, of which 25 were selected by means of reading the respective abstracts. Thereon the scientific reading method was used, organizing the articles into two topics: challenges in the course of nursing education in Brazil, and challenges and perspectives in reorienting the formal nursing education process. It should be observed that resistance to changes, shallow consideration about teaching, and distancing health care services, with reinforcement to the classic dichotomy between thinking and acting, present in a large portion of the teaching practice, are some of the challenges to be faced and overcome in order to improve the contemporary formal nursing education process.
\end{abstract}

DESCRIPTORS: Curriculum. Teaching. Education. Nurse-care.

\section{EL PROCESO DE FORMACIÓN DE LOS ENFERMEROS EN LA ACTUALIDAD: RETOS Y PERSPECTIVAS}

RESUMEN: El objetivo del presente artículo es reflexionar acerca del proceso de formación de los enfermeros en la actualidad. Se trata de una reflexión basada en una investigación bibliográfica en artículos publicados en las bases de datos LILACS y ScIELO, utilizando los siguientes descriptores: currículo, enseñanza, educación, enfermería. Fueron encontrados 39 artículos, de los cuales se seleccionaron 25, por medio de la lectura de los respectivos resúmenes. A continuación, se utilizó el método de lectura científica para la organización del artículo en dos temas: los retos en la trayectoria de la educación en enfermería en el Brasil y, retos y perspectivas en la reorientación del proceso de formación de los enfermeros. Se reitera que la resistencia a los cambios, la poca reflexión sobre la docencia, el distanciamiento de los servicios de salud, el fortalecimiento de la clásica dicotomía entre el pensar y el hacer, presente en gran parte de la práctica docentes, son algunos de los retos a enfrentar y superar para mejora de la formación de los enfermeros en la actualidad.

DESCRIPTORES: Currículo. Enseñanza. Educación. Enfermería. 


\section{INTRODUÇÃO}

As novas configurações do mundo globalizado e seu acelerado processo de modernização científica e tecnológica vêm demandando novas formas de construção do conhecimento, pressionando mudanças no processo de formação de profissionais competentes para o atendimento à saúde da população. Essa necessidade de mudança decorre de elementos, tais como as novas modalidades de organização do mundo do trabalho em saúde e das exigências no perfil de novos profissionais voltados para a transdisciplinaridade na produção do conhecimento.

Nesse contexto, a Lei de Diretrizes e Bases da Educação Nacional (LDB) ${ }^{1}$ fundamenta o processo de formação na educação superior através do desenvolvimento de competências e habilidades; do aperfeiçoamento cultural, técnico e científico do cidadão; da flexibilização dos currículos; da implementação de Projetos Pedagógicos inovadores, numa perspectiva de mudança para a formação profissional. Essas premissas apontam novas configurações para os padrões curriculares, até então vigentes, indicando a necessidade de uma reestruturação dos cursos de graduação com mudanças paradigmáticas no contexto acadêmico, direcionando a construção de Diretrizes Curriculares para cada Curso de Graduação. ${ }^{2}$

Em atendimento à LDB, foi aprovada a Resolução CNE/CES No 03 de 7/11/2001, ${ }^{3}$ que definiu as Diretrizes Curriculares Nacionais para o Curso de Graduação em Enfermagem (DCN/ENF) que, explicitando a necessidade do compromisso com princípios da Reforma Sanitária Brasileira e do Sistema Único de Saúde (SUS), definem os princípios fundamentais para a formação de profissionais críticos, reflexivos, inseridos no contexto histórico-social, pautados em princípios éticos e capazes de intervirem nos problemas/situações da atenção à saúde, onde se insere a atenção à saúde da população.

Essas ações de mudanças implicam a necessidade de profissionais comprometidos com a atenção à saúde; profissionais capazes de compreenderem e re-compreenderem os determinantes da saúde, de transformarem saberes e práticas em relação à atenção à saúde da população, de articularem conhecimentos profissionais com os saberes e práticas envolvidos em saúde, de perceberem a complexidade de suas práticas e de, efetivamente, desenvolverem formas de pensar e agir, reinventando modos de se lidar com a realidade de saúde. ${ }^{2}$

Estudos têm demonstrado que o modelo de ensino reducionista, com conteúdos fracionados e simplificados, vem prevalecendo na formação do profissional enfermeiro. Evidenciam ainda o predomínio de práticas pedagógicas que trazem no seu bojo contradições denominadas fragmentações simplistas, em que ao aluno se oferece um conceito de ser humano integral, único, holístico e multidimensional. Esse conhecimento complexo, entretanto, é transmitido através de métodos de ensino tradicional, rígidos e mecânicos; não sendo oportunizado ao aluno condições de estabelecer relação com o ambiente que está inserido, impossibilitando o desenvolvimento do senso crítico e analítico. ${ }^{4}$

Essa realidade, por sua vez, vem requerer, das instituições formadoras, a implementação de ações de mudanças buscando a reorientação do processo de formação voltado para o desenvolvimento de competências e habilidades, para o exercício de práticas e saberes capazes de darem respostas aos princípios propostos pela Reforma Sanitária e do SUS.

Decorrida quase uma década de aprovação das DCN/ENF em nosso país, observa-se avanços importantes, particularmente no que se refere à construção/reconstrução de Projetos Pedagógicos dos cursos de graduação em enfermagem. Porém muitos desafios ainda necessitam ser superados, visando à transformação do perfil dos futuros profissionais de saúde. ${ }^{2,5-6}$

Alguns cursos já vêm desenvolvendo um processo de mudança no desenvolvimento das suas ações pedagógicas. Entretanto, considerando o quantitativo de, aproximadamente, 700 cursos de graduação em enfermagem, em funcionamento, no nosso país, percebe-se que essa não é a realidade da maioria desses cursos, nos quais ainda prevalece o enfoque do modelo clínico, em que a doença ainda é visualizada como um conjunto de sintomas que requerem intervenções para o alcance de um estado de equilíbrio. As escolas/cursos de enfermagem vêm, portanto, encontrando dificuldades na incorporação das propostas para incrementar as mudanças na formação dos futuros profissionais, estabelecidas pelas DCN/ENF. ${ }^{5-7}$

Mesmo havendo um movimento de transformação na concepção dos currículos de enfermagem, com preocupação nos aspectos filosóficos e pedagógicos, ainda permanece, em algumas realidades, maior ênfase na competência técnicaprofissional, em detrimento do processo de crescimento interno de cada um. ${ }^{8}$

Vale também destacar que em estudos realizados pelo Instituto Nacional de Estudos e 
Pesquisas (INEP) sobre a adequação dos Projetos Pedagógicos dos cursos de enfermagem às DCN/ ENF, publicado no ano de 2006, foi revelado que o índice de aderência dos cursos foi de $72 \%$, o que é considerado um baixo índice frente às expectativas esperadas, levando-se em conta que já havia passado cinco anos de vigência das DCN/ENF, destacando-se que houve um aumento acentuado de novos cursos de graduação em enfermagem, os quais deveriam estar identificados com os postulados preconizados pelas Diretrizes. .,9-10 $^{5}$

Diante desse panorama, o estudo da mudança no processo de formação do enfermeiro emerge como uma prioridade, por considerar o momento atual vivido pelos Cursos de Graduação em Enfermagem, na criação ou adequação dos seus Projetos Pedagógicos.

Frente a essas considerações, cabe, aqui, perguntar: quais os desafios e perspectivas para o processo de formação da(o) enfermeira(o) na contemporaneidade?

Buscando respostas a esse questionamento, este estudo objetiva refletir acerca do processo de formação em enfermagem na contemporaneidade, seus desafios e perspectivas na busca de formar sujeitos éticos, críticos, criativos e reflexivos, capazes de articular saberes e práticas no enfrentamento aos desafios da atenção à saúde da população.

Desse modo, o estudo assume um caráter necessário e relevante, na medida em que pretende contribuir com a transformação do processo de formação do enfermeiro, servindo de subsidio para a reorientação do fazer e saber no desafiante caminho da implementação da mudança na educação em enfermagem no mundo contemporâneo.

Trata-se de um estudo teórico de caráter reflexivo que toma como referência alguns construtos da Reforma Sanitária Brasileira, do SUS e das DCN/ ENF e sua relação com os fatores constituintes do fazer pedagógico na Enfermagem. A elaboração foi subsidiada por uma pesquisa bibliográfica em livros e artigos de periódicos nacionais, através das bases de dados LILACS e SciELO e, Anais deSeminários Nacionais de Diretrizes da Educação em Enfermagem. Os descritores utilizados para selecionar as publicações foram: currículo, ensino, educação, enfermagem. Foram encontrados 39 artigos, oito no LILACS e 31 no SciELO; sendo selecionados 25 através da leitura dos respectivos resumos.

Posteriormente, os artigos selecionados e os demais documentos consultados foram submetidos ao método de leitura científica, ${ }^{11}$ composto pelas seguintes etapas: visão sincrética - que consiste em uma leitura de reconhecimento que objetiva localizar nas fontes, proporcionando uma aproximação preliminar com o tema e a uma leitura seletiva, as informações de acordo com os objetivos do estudo; visão analítica - correspondendo a uma leitura de caráter crítico-reflexiva dos textos selecionados. Esta é acompanhada de uma reflexão, na busca dos significados e na escolha das principais idéias; e, a visão sintética - que constitui a última etapa do referido método que é consolidado através da leitura interpretativa.

Assim, após atendimento das etapas do método da leitura científica, este artigo foi organizado em dois tópicos, abordando - Desafios na trajetória da educação na enfermagem no Brasil e Desafios e perspectivas na reorientação do processo de formação do enfermeiro.

\section{DESAFIOS NA TRAJETÓRIA DA EDUCA- ÇÃO NA ENFERMAGEM NO BRASIL}

O processo de formação do enfermeiro vem sofrendo transformações ao longo dos anos, estando sua trajetória e o perfil dos egressos sempre atrelados ao modelo político-econômico-social vigente do país. Essa trajetória, contudo, não se deu de forma linear; ela encontrou desafios que foram superados nos limites conjunturais de cada momento histórico da sociedade.

No Brasil, a primeira tentativa de sistematização do ensino de enfermagem ocorreu em 1890, quando da criação, na cidade do Rio de Janeiro, da Escola Profissional de Enfermeiros, no Hospício Nacional de Alienados, com a finalidade de preparar enfermeiros para os hospícios e hospitais civis e militares, sem, contudo, adotar a concepção de enfermagem moderna. ${ }^{12-13}$

O currículo, então adotado nessa escola, tomou como referência o modelo francês e incluía noções de propedêutica clínica, anatomia, fisiologia, higiene hospitalar, curativos, cuidados especiais, tratamentos através de banhos, administração e economia das enfermarias. ${ }^{14}$

Por volta de 1901, foi criado, sob a orientação de enfermeiras inglesas, um outro curso, no então Hospital Evangélico (hoje Hospital Samaritano), em São Paulo. Esse curso foi criado com o objetivo de preparar pessoal para o referido hospital que se destinava ao atendimento de estrangeiros residentes no Brasil. ${ }^{12-13}$

Com as repercussões da Primeira Guerra Mundial, a Cruz Vermelha Brasileira deu início, por volta de 1916, na cidade do Rio de Janeiro, a um cur- 
so de enfermagem (Escola Prática de Enfermeiras da Cruz Vermelha), com a finalidade de preparar voluntários para as emergências de guerra. ${ }^{12-14}$

Esses cursos foram criados para atender às necessidades emergenciais de cada momento histórico, sem, contudo, atenderem aos padrões da Enfermagem Moderna, semelhantes aos que, em 1860, já haviam sido estabelecidos em Londres, por Florence Nightingale. Atribui-se a isso, o fato de que durante o predomínio do modelo econômico agrário-exportador, não havia, por parte do Estado, uma política explícita que indicasse uma preocupação com a saúde da população e, consequentemente, com uma mão de obra de enfermagem qualificada. ${ }^{12-14}$

A problemática da Saúde Pública, configurada na crise econômica da década de 1920, constituiu um forte elemento de pressão, demandando novas e amplas respostas do Estado. No conjunto dessas respostas foi criado o Departamento Nacional de Saúde Pública e, posteriormente, em 1923, a Escola de Enfermeiras desse mesmo Departamento, objetivando o preparo teórico e prático de enfermeiras, desenvolvido num período de dois anos e quatro meses, sendo, posteriormente, estendido para um prazo maior a fim de que pudesse incluir os conteúdos gerais e especializados. ${ }^{12-14}$

O processo político da década de 1930 e, mais especificamente, o segundo processo pós-guerra, marcando mudanças nas diretrizes econômicas, na mobilização das classes populares urbanas e determinando um novo esquema de poder, ocasionou a interferência estatal em amplos setores da sociedade, incluindo o setor educação em enfermagem que marcou, nessa época, a sua consolidação como matéria de Lei.

No bojo desse processo ficou evidenciada a necessidade de uma força de trabalho qualificada e com saúde. Essa necessidade, contudo, só foi acionada na década de 1940 com a aceleração do processo de substituição das importações e fortalecimento do processo de industrialização.

Assim, atendendo à lógica de produção de serviços de saúde, o Estado, através da Lei No 775 de 06/08/1949, propôs a ampliação do número de escolas, tornando obrigatória a existência do ensino de enfermagem em todo centro universitário ou sede de faculdades de medicina, além de definir um ensino voltado para a área hospitalar, centrado no modelo clínico e com aderência ao mercado de trabalho à época. ${ }^{15}$

É importante assinalar que o Estado, se por um lado reconheceu o ensino de enfermagem como matéria de Lei, colocando-o ao nível do ensino universitário, em resposta às pressões exercidas pelas profissionais de enfermagem, por outro lado, atendendo ao setor produtivo e empresarial da área da saúde, estabeleceu os fundamentos para a definição do currículo pleno, determinando as condições em que se devia processar a formação da(o) enfermeira(o). O currículo foi esquematizado, as disciplinas foram selecionadas e a ordenação dos estágios passou a ser determinada, foi definida a obrigatoriedade do ensino das ciências físicas e biológicas, sendo restritivo no que se referia às ciências sociais. ${ }^{13}$

O ensino de enfermagem foi, assim, perdendo, gradativamente, o seu enfoque assistencial curativo, passando a ser processado, predominantemente, nos ambientes hospitalares.

Nesse contexto, surgiu a Lei $\mathrm{N}^{\circ} 4024$ de 20 de dezembro de 1961, que fixou as diretrizes e bases da educação nacional. Através dessa Lei, o sistema formal de ensino universitário passou a ser estruturado e reformulado, segundo as determinações do estado.

Ocurrículo mínimo para os Cursos de Graduação em Enfermagem passou a ser fixado através do Parecer No 271 de 19 de outubro de 1962 que estabeleceu um curso geral e duas alternativas para especialização precoce. ${ }^{16}$ Esse parecer considerou as condições culturais e sócio-econômicas do país, que aconselham soluções modestas e de maior rendimento prático, reduziu a duração do curso de graduação em enfermagem de quatro para três anos, reduzindo $36 \%$ da carga horária do curso que, até então, vinha sendo desenvolvido de acordo com a Lei $N^{0} 775 / 49$. Com esse novo currículo, foi feita a exclusão de algumas disciplinas do tronco profissional comum do curso de graduação, tais como a Enfermagem de Saúde Pública e Ciências Sociais. A disciplina de Enfermagem de Saúde Pública deixou de ser uma disciplina obrigatória e passou a ser uma especialização de caráter optativo. ${ }^{12-14}$

Com a Lei $\mathrm{N}^{\circ} 5.540$ de 28 de novembro de 1968, foram fixadas as normas de organização e funcionamento do ensino superior e sua articulação com a escola média. Através dessa Lei, implanta-se uma política educacional que se autonomeia Reforma Universitária. ${ }^{13-14}$ Através dessa Lei, o então Conselho Federal de Educação (CFE) passou a exigir a revisão dos currículos mínimos dos cursos superiores, a fim de que os mesmos se adequassem aos planos de desenvolvimento do país que, naquele momento, estavam incorporados ao crescimento industrial. 
Essa proposta, após sofrer transformações, foi transformada em anteprojeto do currículo mínimo que deu origem ao Parecer $\mathrm{N}^{\circ} 163$ de 27 de janeiro de 1972 da Comissão Central de Revisão de Currículos e aprovado pela Resolução $\mathrm{N}^{\circ} 4$ de 25 de fevereiro do mesmo ano, do então CFE.

Esse novo currículo passou a ser constituído de três partes: pré-profissional, tronco profissional comum e habilitações. O pré-profissional incluía conhecimentos de biologia, ciências morfológicas, ciências fisiológicas, patologia, ciências do comportamento e introdução à saúde pública. O tronco profissional comum incluía: introdução à enfermagem, enfermagem médico-cirúrgica, enfermagem materno-infantil, enfermagem psiquiátrica, enfermagem em doenças transmissíveis, exercício da enfermagem, didática aplicada à enfermagem e administração aplicada à enfermagem. As habilitações, por opção das alunas, abrangiam a enfermagem médico-cirúrgica, enfermagem obstétrica e enfermagem de saúde pública. ${ }^{17}$

O novo currículo permaneceu com uma densa carga horária concentrada nas disciplinas da assistência curativa, assim como manteve a exclusão da enfermagem em saúde pública do tronco profissional comum, permanecendo, em essência, a ênfase nos aspectos curativos e, portanto, a diluição a concepção do social em função da concepção predominante do biológico.

Dentre os diversos movimentos políticos e sociais que eclodiram nas décadas de 1980 e 1990, e que tiveram influência no processo de formação da(o) enfermeira(o), merecem ser destacadas a VIII Conferência Nacional de Saúde, em 1986, a promulgação da Constituição Brasileira, em 1988, e a criação do SUS após a aprovação da Lei Orgânica da Saúde No 8080/90, pois se constituíram em expressão de um processo de luta de diferentes atores da sociedade por ampliação de direitos sociais.

A Associação Brasileira de Enfermagem (ABEn), como um dos atores engajados nesse processo de luta, desencadeou um amplo debate por meio dos Seminários Nacionais e Regionais sobre "Perfil e Competência de Enfermeiros" e "Proposta de Currículos Mínimos de Enfermagem", mobilizando docentes, discentes e profissionais dos serviços de saúde, objetivando a construção coletiva de um projeto educacional para a enfermagem brasileira. A troca de experiências e a riqueza das discussões geradas nesse movimento subsidiaram o Parecer 314/94 do, então, CFE, homologado pela Portaria No 1.721 do Ministério da Educação, em
15 de dezembro de1994, surgindo, assim, um novo currículo para os cursos de graduação em enfermagem. Esse novo currículo passou a ser constituído por quatro eixos temáticos, a saber: Bases Biológicas e Sociais da Enfermagem, Fundamentos de Enfermagem, Assistência de Enfermagem e Administração em Enfermagem. ${ }^{18}$

Além de definir os eixos temáticos e o percentual da carga horária dos mesmos, a Portaria $\mathrm{N}^{\circ}$ 1.721/94 definiu, também, a carga horária mínima do curso, em 3.500 horas, e a sua duração em, no mínimo, quatro anos (ou oito semestres letivos) e, no máximo, seis anos (12 semestres letivos).

Esse currículo, apesar de contemplar algumas propostas apresentadas pela categoria das profissionais de enfermagem, gerou algumas insatisfações, tais como aquelas relacionadas à ausência das disciplinas da área de educação, desconsiderando a função educativa da enfermagem. Outra insatisfação gerada pelo novo currículo foi decorrente da delimitação do percentual da carga horária dos eixos temáticos, que configurava um controle sobre o processo de formação da(o) enfermeira(o), limitando o perfil do profissional generalista e desconsiderando as características institucionais e regionais onde os cursos se inseriam.

Essas insatisfações frente ao novo currículo eram manifestadas nos diversos eventos científicos da área, particularmente nos Seminários Nacionais de Diretrizes para a Educação em Enfermagem (SENADEns), criados, pela ABEn, a partir de 1994 e que trouxeram contribuições significativas para a construção das DCN/ENF, além de se constituírem em espaços para aprofundamento da construção coletiva das políticas e propostas que dizem respeito à educação em enfermagem. ${ }^{19}$

As DCN/ENF foram concretizadas com base nas propostas que emergiram da mobilização das(os) enfermeiras(os), através da sua associação de classe, de entidades educacionais e de setores da sociedade civil interessados nas mudanças da formação na área da saúde. Essas diretrizes expressam conceitos originários dos movimentos por mudanças na educação em enfermagem, explicitando a necessidade do compromisso com princípios da Reforma Sanitária Brasileira e do SUS. Elas se constituem, destarte, como produto de uma construção social e histórica, e trazem, no seu conteúdo, os posicionamentos da enfermagem brasileira como ponto de partida para as mudanças necessárias à formação da(o) enfermeira(o) na contemporaneidade. ${ }^{19}$ 
O processo de formação da(o) enfermeira(o) na contemporaneidade aponta, pois, para a capacitação da(o) profissional para o exercício das competências gerais e específicas, além de habilidades pautadas nas concepções do aluno como sujeito do seu processo de formação, da articulação entre teoria e prática, da diversificação dos cenários de aprendizagem, de metodologias ativas, da articulação da pesquisa com o ensino e extensão, da flexibilidade curricular, da interdisciplinaridade, da incorporação de atividades complementares, da avaliação da aprendizagem, do processo de acompanhamento, avaliação e gestão do curso, assim como da terminalidade do curso. ${ }^{19}$

Elas indicam, também, as diretrizes para os eixos temáticos que devem contemplar as Ciências Biológicas e da Saúde, as Ciências Humanas e Sociais e as Ciências da Enfermagem, nas quais se incluem Fundamentos de Enfermagem, Assistência de Enfermagem, Administração de Enfermagem e Ensino de Enfermagem. Ao contrário da Portaria No 1.721/94, a Resolução No 03/2001 do CNE não estabeleceu percentuais para os conteúdos, nem definiu duração e carga horária para o curso. Definiu, entretanto, que o Estágio Curricular Supervisionado deva ser oferecido nos dois últimos semestres do curso, com carga horária de, no mínimo, 20\% da carga horária total do curso e que deva contemplar a rede básica e a rede hospitalar. ${ }^{19}$

No momento, as escolas/cursos encontram-se em fase de adequação dos seus Projetos Pedagógicos e matrizes curriculares às DCN/ ENF. E, nessa etapa, muitos desafios estão sendo encontrados no processo de reorientação do fazer e saber, na implementação da mudança na formação do enfermeiro, pois esta implica mudar paradigmas, fazer rupturas em práticas e crenças internalizadas. O momento é, pois, de enfrentamento a esses desafios, em busca do fortalecimento da mudança no processo de formação $\mathrm{da}(\mathrm{o})$ enfermeira(o) e do SUS.

\section{DESAFIOS E PERSPECTIVAS NA REO- RIENTAÇÃO DO PROCESSO DE FORMA- ÇÃO DA(O) ENFERMEIRA(O)}

O processo e formação da(o) enfermeira(o), na contemporaneidade, se constitui num grande desafio, que é o de formar profissionais com competência técnica e política, dotados de conhecimento, raciocínio, percepção e sensibilidade para as questões da vida e da sociedade, devendo estar capacitados para intervir em contextos de incertezas e complexidade.

O enfrentamento aos desafios da contemporaneidade requer uma reestruturação pedagógica, fundamentada nos pilares da educação contemporânea no sentido de formar profissionais com capacidade de aprender a aprender, aprender a conhecer, aprender a fazer, aprender a viver junto e aprender a ser, ${ }^{19-20}$ garantindo a capacitação de enfermeiros com competência para atuar com autonomia e discernimento, a fim de assegurar a integralidade da atenção à saúde com qualidade, eficiência e resolutividade.

Entende-se, pois, que o aprender a conhecer, ${ }^{20-21}$ envolve o aprender a conhecer a nova realidade do processo de formação, a construir um novo olhar sobre novas formas de atenção à saúde, a pensar propostas de reformulação dos projetos pedagógicos tradicionais, a desconstruir e reconstruir o conhecimento na área da enfermagem. Entende-se, também, que o aprender a fazer ${ }^{20-21}$ no fazer cotidiano do ensino da enfermagem, oferece oportunidades de desenvolvimento de competências para a transformação de saberes e práticas em relação à atenção à saúde, para empreender ações voltadas para a percepção do cuidado como elemento de transformação do viver, o exercício da ética, da solidariedade e da compreensão do sujeito no seu cotidiano. O aprender a viver junto, ${ }^{20-21}$ nas ações pedagógicas do ensino da enfermagem, apresenta possibilidades para a compreensão do paciente e sua família, para o desenvolvimento do trabalho em equipe, para a criação de outros modos de pensar, viver, olhar e trabalhar com a saúde. O aprender a ser, ${ }^{20-21}$ favorece as condições para o desenvolvimento integral do profissional, com sensibilidade, responsabilidade pessoal, sentido ético e estético, pensamento autônomo e crítico, criatividade, iniciativa e rigor científico.

A formação dos enfermeiros fundamentada nesses pilares tem como perspectiva o desenvolvimento de atividades de educação para oSUS, de interação entre ensino, serviço e controle social em saúde, pautado num projeto pedagógico inovador, construíd o coletivamente e com forte inserção nas necessidades de saúde da população na sua concepção ampliada e na concepção social de cuidado de enfermagem.

Neste sentido, a realidade coloca o desafio, não só da elaboração de projetos pedagógicos e desenhos curriculares, mas o de uma prática pedagógica que possibilite uma formação de enfermeiros comprometidos com o enfrentamento dos 
graves problemas de saúde da nossa sociedade, o que significa não perder a perspectiva da integralidade da atenção, da equidade, da eficiência e da eficácia.

A contemporaneidade necessita, pois, de profissionais de saúde que atuem como sujeitos sociais comprometidos com a democracia e a emancipação humana. Sujeitos capazes de inovar, mas, sobretudo, de humanizar as inovações.

No contexto dos desafios, destacam-se aqueles que estão relacionados à aquisição, desenvolvimento e avaliação das competências e das habilidades, dos conteúdos essenciais, das práticas e estágios e das atividades complementares. Neste âmbito, salienta-se também ser as definições sobre essas competências pouco claras, não havendo, tampouco, a obtenção de um consenso sobre elas. Entretanto, são exatamente essas competências que irão conciliar o projeto pedagógico dos cursos, as necessidades e os objetivos da formação de enfermeiras(os). ${ }^{2}$

Um dos maiores desafios continua sendo o de aprofundar as discussões e de tornar claro à comunidade universitária, que o desenvolvimento de habilidades passa pelo conhecimento através das disciplinas e outras atividades curriculares formais, mas não se restringe a ele; passa pela necessidade de desenvolver a competência de trabalhar a parte prática deste conhecimento, num processo formativo de verdadeiros cidadãos, capazes de responder aos constantes desafios impostos pela sociedade e, mais especificamente, pelo setor saúde, promovendo oportunidades de reflexão sobre o trabalho/ fazer pedagógico na saúde e na enfermagem.

Outros desafios no incremento das mudanças na formação dos futuros profissionais, estabelecidas pelas DCN/ENF, são aqueles relativos à aquisição/desenvolvimento/avaliação de competências e habilidades, aos conteúdos essenciais, às práticas/estágios, à flexibilização curricular, à incorporação de atividades complementares ao eixo fundamental do processo formativo, à operacionalização da inter e transdisciplinaridade. Observa-se, também, que ainda não existe uma clara definição sobre as competências para a formação da(o) enfermeira(o) e para a obtenção de consenso sobre essas competências.

Esses desafios encontrados na reestruturação do processo de formação com base nesses pilares da educação contemporânea indicam perspectivas, tais como:

- O aluno como sujeito do seu processo de formação direcionado para o desenvolvimento da capacidade de aprender a aprender, de articular conhecimentos, de desenvolver habilidades e atitudes; de saber buscar informações para resolução de problemas e de enfrentamento a situações de imprevisibilidade, da capacidade de agir com eficácia frente às mais diversas situações, apoiandose em conhecimentos anteriormente adquiridos, mas sem limitar-se a eles.

- Formação por competências, indicando a necessidade de experiências e oportunidades nos serviços de atenção à saúde e possibilitando o desenvolvimento para além do cognitivo. Isto significa a capacidade de propor estratégias para o saber agir e transformar as práticas de atenção à saúde, através da identificação e mobilização de conhecimentos que dão suporte para a solução de problemas. ${ }^{22}$

- Articulação entre teoria e prática no ensino de enfermagem que, por sua vez, pressupõe ações pedagógicas que, ultrapassando os muros da academia, indicam a necessidade da inserção dos sujeitos do processo de formação nos espaços de encontro, de produção do cuidado, de produção de novas subjetividades. Enfim, nos espaços de atenção à saúde, fazendo com que a formação em enfermagem seja centrada numa contínua aproximação do mundo do ensino com o mundo do trabalho.

- Interação educador-educando, voltada especialmente para a reelaboração dos conhecimentos e habilidades aprendidas e a produção de novos conhecimentos, tendo o professor a responsabilidade de articular metodologias de ensino, caracterizadas por variedade de atividades estimuladoras da criatividade e de superação de obstáculos pelos alunos.

- Utilização das estratégias pedagógicas que possibilitem, aos futuros egressos, compreenderem e re-compreenderem os determinantes da saúde, transformarem saberes e práticas em relação à atenção à saúde da população, articularem conhecimentos profissionais com os saberes e práticas envolvidos em saúde, perceberem a complexidade de suas práticas e de, efetivamente, desenvolverem formas de pensar e agir, reinventando modos de lidar com a realidade de saúde.

- Diversificação dos cenários de aprendizagem, de metodologias ativas, da articulação da pesquisa com o ensino e extensão, da flexibilidade curricular, da interdisciplinaridade, da incorporação de atividades complementares, da avaliação da aprendizagem, do processo de acompanhamento, avaliação e gestão do curso, assim como da terminalidade do curso. 
Assim, compreende-se que a formação do profissional enfermeiro em uma perspectiva críticocriativa requer uma revisão nos modos de ensinaraprender enfermagem, estando esse desafio colocado não só pelo reconhecimento da complexidade da sociedade contemporânea como também pelas novas demandas legais, traduzidas pelas DCN. Desse modo considera-se também esse como um dos desafios para as instituições formadoras, pois requer uma profunda análise das concepções pedagógicas em estreita ligação com as práticas concretas, nos diversos cenários de aprendizagem, que envolvem academia e serviços de saúde, não esquecendo que nesse processo de mudança, existe confronto com o paradigma hegemônico orientador da formação em enfermagem, fortemente marcada pela racionalidade positivista da ciência moderna. ${ }^{23}$

\section{CONSIDERAÇÕES FINAIS}

O processo de formação demandado pelas transformações sociais implica, pois, uma abordagem de continuidade e de ruptura, ou seja, a continuidade do processo de evolução do mundo, das fronteiras, das tecnologias, dos estilos de vida que hoje requerem flexibilidade e criatividade dos trabalhadores; a ruptura com as práticas pedagógicas que não capacitam os indivíduos para o agir frente à complexidade das situações do cotidiano. Implica, também, um diálogo entre saberes e práticas, na articulação teoria/ prática como elementos fundamentais para o estabelecimento de espaços para o desenvolvimento de metodologias para o desenvolvimento de competências, fazendo emergir a necessidade de desconstrução do paradigma do conhecimento dicotomizado entre o saber e o fazer, entre a teoria e a prática. Trata-se, pois, de uma relação dialética que aciona um conjunto de saberes que dão sustentação às ações de atenção à saúde, desenvolvidas no SUS.

Reitera-se, ainda, que a resistência às mudanças, a pouca reflexão sobre a docência, o distanciamento dos serviços de saúde, com o reforço à clássica dicotomia entre o pensar e o fazer, além da fragmentação e tecnicismo, presentes em boa parte da prática dos docentes, constituem algumas das contradições que necessitam de enfrentamento e superação para melhoria da formação do enfermeiro na contemporaneidade.

Enfrentar os limites e os desafios no processo de formação de profissional enfermeiro significa investir e comprometer-se com as mudanças, exigindo dos envolvidos no processo interação, integração, comprometimento e qualificação.
Desse modo, as inovações requerem uma atitude coletiva, aberta, envolvendo docentes, discentes, gestores e profissionais da área. Assim, pode-se inferir que a formação de um perfil de enfermeiro com abordagem generalista, humanista, critica e reflexiva só poderá ser alcançada com a adoção de práticas pedagógicas ativas que tenham o aluno como principal sujeito do seu processo de aprendizagem e o professor como facilitador deste processo, assegurando desta forma o desenvolvimento de competências que perpassem o modelo tradicional de formação profissional, que privilegia o conhecimento teórico e memorizado para ações que possibilitem a interrelação das competências e habilidades estabelecidas, através da empregabilidade dos conceitos da interdisciplinaridade e multidisciplinaridade no processo de formação do profissional enfermeiro.

Mais que um projeto pedagógico elaborado e um currículo desenhado, é necessário assegurar espaços para essa nova prática pedagógica, de políticas nacionais e locais de educação e saúde voltados para os interesses do povo brasileiro.

O processo de formação do enfermeiro vem requer das instituições formadoras, a implementação de ações de mudanças buscando a reorientação do processo de formação voltado para o desenvolvimento de competências e habilidades, para o exercício de práticas e saberes capazes de darem respostas aos princípios propostos pela Reforma Sanitária e do SUS.

Algumas escolas vêm buscando estratégias para superação desses desafios, tais como: discussão em oficinas pedagógicas sobre formação crítica e reflexiva e conceito de competências; formação de comissões permanentes de avaliação; inserção dos alunos em núcleos de pesquisa e orientação acadêmica, capacitação permanente de docentes; busca incessante de metodologias que articulem teoria prática, dentre outras.

\section{REFERÊNCIAS}

1. Ministério da Educação (BR), Lei No 9.394 em 20 de dezembro de 1996: estabelece as diretrizes e bases da educação nacional. Diário Oficial da União, Brasília (DF) 1996 dez 23; 34 (248) Seção 1:27.p.833-41.

2. Fernandes JD, Xavier I, Ceribeli IPF, Bianco MH, Maeda D, Rodrigues MV. Diretrizes Curriculares e estratégias para implantação de uma nova proposta pedagógica. Rev Esc Enferm USP. 2005 Out-Dez; 39(4):443-9.

3. Ministério da Educação (BR), Conselho Nacional de Educação. Câmara de Educação Superior. Resolução 
CNE/CES No 3 de 7 de novembro de 2001: Diretrizes Curriculares Nacionais do Curso de Graduação em Enfermagem. Brasília (DF); 2001.

4. Moya JLM, Esteban MPS. La complejidad del cuidado y el cuidado de la complejidad: un tránsito pedagógico de los reduccionismos fragmentantes a las lógicas no líneales de la complejidad. Texto Contexto Enferm. 2006 Abr-Jun; 15(2):312-9.

5. Lopes Neto D, Teixeira E, Vale EG, Cunha, SF, Xavier IM, Fernandes JD, et al. Um olhar sobre as avaliações dos cursos de graduação em enfermagem. Rev Bras Enferm. 2008 Jan-Fev; 61(1):46-53.

6. Ceccim RB, Feuerwerker LCM. Mudança na graduação das profissões de saúde sob o eixo da integralidade. Cad Saúde Pública [online]. 2004 SetOut [acesso 2006 Jul 18]; 20 (5):1400-10. Disponível em: http://www.scielo.br/pdf/csp/v20n5/36.pdf

7. Fernandes JD, Oliva DSR, Vieira TT, Sadigursky D. Dimensão ética do fazer cotidiano no processo de formação da(o) enfermeira(o). Rev Esc Enferm USP. 2008 Jun; 42(2):396-403.

8. Ito EE, Peres AM, Takahashi RT, Leite MMJ. O ensino de enfermagem e as Diretrizes Curriculares Nacionais: utopia x realidade. Rev Esc Enferm USP. 2006 Dez; 40(4):570-5.

9. Lopes Neto D. Teixeira E, Vale EG, Cunha, SF, Xavier IM, Fernandes JD, et al. Aderência dos cursos de graduação em enfermagem às Diretrizes Curriculares Nacionais. Rev Bras Enferm. Nov-Dez; 60(6):627-34.

10. Ministério da Saúde, Ministério da Educação (BR), A aderência dos cursos de graduação em enfermagem, medicina e odontologia às diretrizes curriculares nacionais. Brasília (DF): MS/MEC; 2006.

11. Cervo AI, Bervian PA. Metodologia científica. $5^{\mathrm{a}}$ ed. São Paulo (SP): PrenticeHall, 2002.

12. Alcântara G. A enfermagem como categoria profissional: obstáculos à sua expansão na sociedade brasileira [tese concurso Professor Catedrático]. Ribeirão Preto (SP): Universidade de São Paulo. Escola de Enfermagem de Ribeirão Preto; 1963.
13. Fernandes J.D. O ensino de enfermagem e de enfermagem psiquiátrica no Brasil [dissertação]. Salvador (BA): Universidade Federal da Bahia. Departamento de Medicina Preventiva da Faculdade de Medicina; 1982.

14. Fernandes J.D. Expansão do ensino de enfermagem no Brasil [tese]. Salvador (BA): Universidade Federal da Bahia. Escola de Enfermagem; 1988.

15. Ministério da Educação (BR), Fundação Serviços de Saúde Pública. Enfermagem: legislação e assuntos correlatos. $3^{\mathrm{a}}$ ed. Rio de Janeiro (RJ): FSESP; 1974.

16. Conselho Federal de Educação (BR), Parecer $N^{\circ}$ 271 de 19 de setembro de 1962. Currículo do Curso de Enfermagem. Documenta. Brasília (DF) 1962, 10(12):54-60.

17. Ministério da Saúde (BR), Fundação Serviços de Saúde Pública. Enfermagem: legislação e assuntos correlatos. 3a ed. Rio de Janeiro (RJ): MS; 1974. p.249-53.

18. Ministério da Educação (BR), Portaria $N^{\circ} 1.721$ de 16 de dezembro de 1994: currículo mínimo do curso de enfermagem. Diário Oficial da República Federativa do Brasil: Brasília (DF) 1994 dez 16; Seção 1:19301-2.

19. Fernandes JD. A trajetória do ensino de graduação em enfermagem no Brasil. In: Teixeira E, Vale EG, Fernandes JD, DeSordi MRL, organizadores. Oensino de graduação em enfermagem no Brasil: o ontem, o hoje e o amanhã. Brasília (DF): INEP; 2006.

20. Delors J. Educação: um tesouro a descobrir. Lisboa (PT): UNESCO/ASA; 1996.

21. Gadotti M. Perspectivas atuais da educação. Porto Alegre (RS): Artes Médica, 2000.

22. Perrenaud P. Ensinar: agir na urgência, decidir na incerteza. Porto Alegre (RS): Artes Médicas; 2001.

23. Prado ML, Riebnitz KS, Gelbcke FL. Aprendendo a cuidar: a sensibilidade como elemento plasmático para formação da profissional crítico-criativa em enfermagem. Texto Contexto Enferm. 2006 Abr-Jun; 15(2):296-302. 